\title{
La legislación mexicana en torno a la actividad turística
}

DOI: 10.22403/UQROOMX/TYP04/07

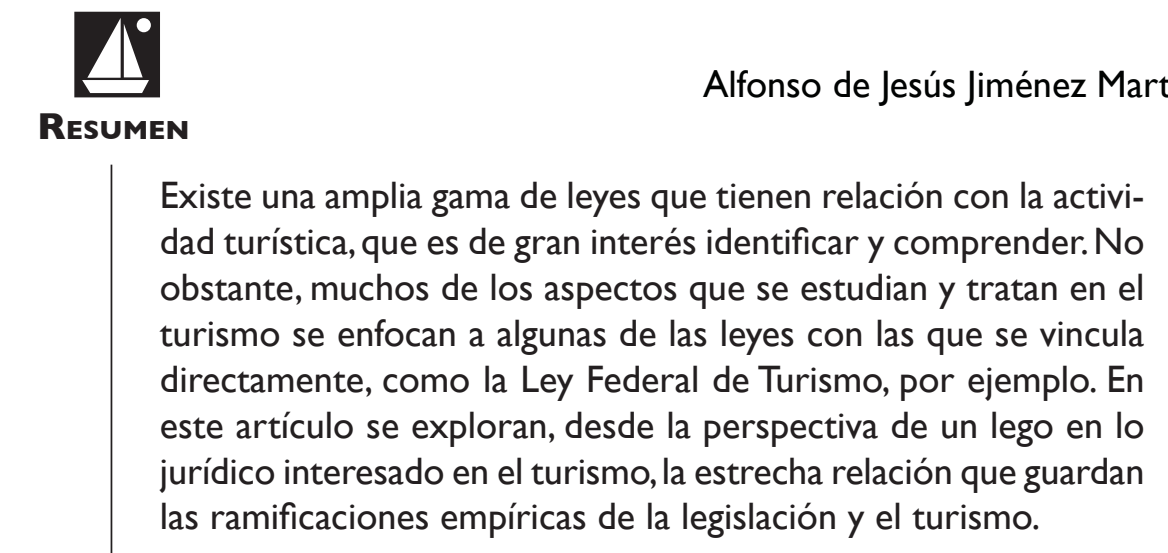

Palabras $\mid$ México, multidimensionalidad, legislación, turismo.

CLAVE

*Departamento de Turismo Sustentable y Gestión Hotelera, Universidad del Caribe 
La legislación mexicana en

torno a la actividad turística

\section{Introducción}

Las actividades del hombre están enmarcadas por convenciones de sociedades que se precian de vivir en un Estado de Derecho, lo que se refiere a los acuerdos establecidos para lograr una convivencia armónica, en un marco que define, encauza y enjuicia las acciones de los miembros de esas sociedades. En el turismo, la aplicabilidad del Derecho se puede extender a ámbitos que se encuentran más allá del propio territorio nacional; no obstante, cuando se habla de la relación entre legislación y turismo en México, generalmente se constriñe el tema a la Ley Federal de Turismo, cuando es muy amplia la gama de leyes y códigos que son pertinentes y aplicables en la práctica turística, pero depende de cada instancia interesada la función y el enfoque que se adopte.

En el presente trabajo se hace una revisión general de las leyes vinculadas al turismo desde su condición multitemática (León, 2002 [2000]; Olivera, 1988 [1970]), la cual, junto con su concomitante complicación, no es un asunto nuevo. En la década de los ochenta Olivera (1988) afirmaba que si bien el marco legislativo que regulaba al turismo en México se había ampliado, faltaba mucho por hacer. Olivera (1988: I0-I I) describe la integración del Comité Oficial de Turismo (de la Comisión de Turismo creada en 1933) con diversas dependencias de la administración pública; con ello se reconoce la multiplicidad de temas relacionados con el turismo, pero la adscripción de la comisión a la Secretaría de Economía en esa época evidencia el énfasis en el interés económico.

A pesar de los avances en la visualización in extenso del turismo en relación con la sociedad, está pendiente la descripción específica de la legislación mexicana' en el contexto amplio de la actividad turística. ${ }^{2}$ León Gómez (2002) describe las normas más importantes relacionadas con los extranjeros (migración), el tema del consumo, de los contratos, de las normas de calidad y oficiales, así como algunas vinculadas con el transporte y con los servicios de

'El profesor Ventura Enrique Mota Flores, del Departamento de Turismo de la Universidad del Caribe, realiza un estudio de mayor alcance y detalle, con una orientación y técnica eminentemente jurídica.

${ }^{2}$ Olivera (1988) observa y describe la historia y evolución de la organización administrativa del turismo; se focaliza en la Ley Federal de Turismo, en las diferentes leyes emitidas en el tema específicamente relacionado con el extranjero, disposiciones internacionales, convenciones internacionales celebradas por México, así como en las disposiciones federales que determinaban la estructura administrativa del turismo a nivel federal en su momento. 
marina, pero deja de lado otros temas relevantes; por ejemplo, los relacionados con el medioambiente. ${ }^{3}$

Por lo anterior, en este artículo se pretende enunciar todas las conexiones de la legislación mexicana con la actividad turística. El trabajo se organiza a partir de la conceptualización y organización temática del turismo que utiliza la Teoría General de Sistemas descrita por Jiménez (2005) en función de cuatro dimensiones de análisis (Jiménez, 2005: 68), a las que se puede añadir el contexto jurídico como una dimensión más del análisis turístico en los tres diferentes ámbitos de acción descritos en ese texto: receptor, emisor y vinculación. El presente estudio, sin embargo, no tiene como objetivo cuestionar o definir aspectos que le competen a la técnica jurídica, describe únicamente el interés -y la necesidad- de vincular el marco jurídico, en un sentido amplio, con la variada naturaleza multidimensional, áreas con las cuales el turismo está interconectado.

\section{El amplio contexto de la legislación con efectos en el turismo}

En primer término se plantea la incidencia de la legislación en el turismo a diferentes escalas operativas. En la propuesta de Jiménez (2005: 35-45) se consideran escalas de nivel internacional, diferenciadas a partir de cierto aglutinamiento de los sistemas-países. De esta forma, en las escalas de supersistemas e hipersistemas y en los tres ámbitos descritos, se relaciona el turismo con el Derecho Internacional tanto público como privado.

El Derecho Internacional Público regula acciones internacionales y aquellas que tienen como sujetos a los diferentes Estados y los intereses que entrañan cuestiones de soberanía. Por esta razón, contextualiza la relación de las líneas aéreas de un determinado país, cuyo gobierno negocia con otro las condiciones del servicio aéreo de manera bilateral. Es también, en la esfera del Derecho Internacional Público donde se definen los límites del mar patrimonial y del mar territorial, que establecen la soberanía de la pesca en alta mar y que

${ }^{3}$ León Gómez (2000) describe 19 leyes (la Constitución y diversas normas, convenios, decretos y declaratorias) vinculadas con la actividad turística, aunque las enuncia circunscritas al marco jurídico de la Secretaría de Turismo y no en un marco extenso que las relacione entre sí diversas y exponga su vinculación con la actividad turística. 
puede por ello influir, para plantearlo en términos de interés turístico, en la pesca deportiva así como en el contexto jurídico de los viajes de recreo que involucran los juegos de azar en los casinos de los cruceros que, para operar, tiene que encontrarse en aguas internacionales por ser una actividad prohibida en territorio nacional (es el caso, por ejemplo, de la embarcación anclada en la Bahía de Chetumal).

Por otra parte, algunas empresas transnacionales de hotelería o algunos mecanismos de financiamiento y ciertas negociaciones de empresas extranjeras, se encuentran en la esfera de las responsabilidades que consigna el Derecho Internacional Privado, que trata de las relaciones que un Estado mantiene con individuos que no sean sus ciudadanos; este sería el caso, por ejemplo, de las aerolíneas en su relación con las autoridades de otro país. En realidad parece existir cierta indefinición que resulta un tanto sorprendente porque con la globalización las relaciones comerciales entre individuos (empresas o personas) y los Estados son ahora más frecuentes. Incluso, León Gómez (2002: 23-24) considera el Derecho Turístico dentro del Derecho Internacional Privado.

La diversificación del Derecho en las actividades turísticas refiere contextos tanto a nivel macro como micro, de las actividades económicas y comerciales, así como las posibilidades y contexto del desplazamiento de turistas entre diferentes países. La Constitución mexicana garantiza para nacionales y extranjeros el libre tránsito de personas, y ésta sería la primera condición jurídica que aplica a la condición turística. Sin ella no existe ninguna otra.

A escala del sistema-país se aplica el conjunto de leyes que constituyen el cuerpo jurídico en el que se desarrolla la actividad turística y ofrece el contexto en el que debemos entenderla y encauzarla. Pero la dinámica de su aprovechamiento rebasa con mucho las estipulaciones de la Ley Federal de Turismo ${ }^{4}$ -instrumento normativo que podría suponerse, equivocadamente, como el meollo del asunto-, o de la Ley General de Población, que establece las regulaciones de las nacionalidades preferidas - $y$ de las excluidas- para su ingreso al país. Ejemplo de otras leyes que vinculan la actividad turística con diferentes ramas del Derecho, todas en el ámbito receptor del sistema-país, se mencionan a continuación.

${ }^{4}$ Las últimas reformas son del 19 de abril de 1999 donde se constituye el Consejo de Promoción Turística de México y se le asignan recursos a la promoción, derivados de una parte de los impuestos migratorios (DNI). 
La Ley del Mar define los espacios marítimos del territorio nacional (mar territorial, plataforma continental y zona económica de uso exclusivo) y las zonas e instalaciones marítimas mexicanas. Sin embargo, en la Ley General de Bienes Nacionales se incluye la definición y los usos de la Zona Federal Marítimo Terrestre cuyas cuotas (establecidas en la Ley Federal de Derechos) son la fuente de ingresos más federalizadas y constituyen una buena parte del ingreso fiscal de los municipios que se encuentran en los destinos turísticos de playa. Esta ley identifica, regula y controla el aprovechamiento del litoral donde la presencia antrópica genera apetencias (por ejemplo territoriales) y problemas que deben ser resueltos por las administraciones municipales.

En relación con el transporte-circulación vital en el sistema turístico-, la Ley de Navegación y de Comercio sólo mantiene las estipulaciones relativas al aseguramiento de las embarcaciones, de la ley de 1963; la más actualizada Ley de Navegación establece los aspectos más importantes de la propiedad y explotación de embarcaciones y del transporte de pasajeros. Estas leyes rigen las maniobras de yates y cruceros que arriban a nuestro país -algunos con pretensiones bucaneras-, así como el tráfico marítimo del litoral mexicano. Su equivalente para el espacio aéreo es la Ley de Aviación Civil, que norma el servicio público y privado del transporte aéreo, matrículas, contratos de aeronaves y otras relativas.

En el mismo orden de ideas, la Ley de Puertos regula las operaciones específicas de las terminales y su equivalente en el servicio aéreo; y la Ley de Aeropuertos, los términos de las concesiones, servicios y tarifas para los diferentes tipos de usuarios. Equivalente a las anteriores pero en el ámbito del transporte terrestre, se tienen las disposiciones específicas en la Ley de Vías Generales de Comunicación así como la Ley de Caminos, Puentes y Autotransporte Federal.

En el contexto del territorio y sus posibilidades de desarrollo, la Ley Federal Agraria establece la normatividad para que ciertos territorios puedan ser aprovechados de diferente forma, incluida la turística. En este contexto se puede insertar la Ley de Desarrollo Rural Sustentable que se propone fomentar el desarrollo económico de las áreas rurales, frecuentemente marginadas, donde el turismo puede ser, al menos potencialmente, una opción más de desarrollo. Vinculada con ellas se encuentra la Ley General de Desarrollo Forestal Sustentable que tiene por objeto normar la utilización sustentable y la protección de 
los bosques y las tierras forestales en beneficio de las generaciones actuales y futuras. A estas leyes se vincula la Ley de Aguas Nacionales, que tiene por objeto regular la explotación, uso y aprovechamiento, distribución y control así como la preservación de la cantidad y calidad del agua para lograr un desarrollo integral, avocándose también a la protección de los mantos acuíferos.

Por otra parte, la Ley de Protección Ambiental y Equilibrio Ecológico determina el marco para la operación de nuevos desarrollos turísticos basados en la explotación de recursos naturales. En esta ley se inserta el Sistema Nacional de Áreas Protegidas que norma el aprovechamiento turístico potencial; su importancia está a la vista cuando el desarrollo turístico involucra ecosistemas frágiles con respecto a los cuales la proliferación de centros y establecimientos turísticos obliga a preguntarnos la razón de la ineficacia de esta ley en México.

De la mano de aquélla van la Ley de Asentamientos Humanos, que dispone la forma en la que se visualiza el desarrollo urbano de las localidades; $y$ la Ley General de Salud, que establece las regulaciones de sanidad marítima, aérea y terrestre; para la publicidad, productos cosméticos, servicios de belleza (spa) y salud, en esta última se incluyen las enfermedades transmisibles, como el sida.

Con respecto a la inversión turística, la Ley de Inversiones Extranjeras define la normatividad de las propiedades en litorales y playas para el comercio turístico internacional que enfrentó formas sofisticadas de propiedad en un pasado que parece lejano -como los mecanismos de simulación conocidos como prestanombres-. Asociada a esta legislación se encuentra la Ley General de Títulos y Operaciones de Crédito que regula las condiciones de operación de los fideicomisos mediante los cuales los extranjeros pueden tener propiedades privadas en áreas con restricciones constitucionales para ello.

Para el funcionamiento del sector público la Ley Federal de Derechos establece el marco regulatorio para la captación de ingresos mediante el cobro de derechos de todo tipo:desde los permisos de pesca y caza hasta los de atraque de embarcaciones y por el uso de la Zona Federal Marítimo Terrestre, así como el del pago de Derechos para no Inmigrantes (DNI) - personas que se internan al país en calidad de turistas, personas de negocios y transmigrantes).

En relación con el patrimonio de México, tan importante para la función turística, existen dos leyes básicas: a) la Ley de Bienes Nacionales que define los bienes de dominio público, los muebles e inmuebles del dominio privado, 
así como el inventario de los bienes y recursos de la nación, y b) la Ley Federal de Monumentos y Zonas Arqueológicas, Artísticas e Históricas que define los límites de responsabilidad administrativa del patrimonio cultural de México y ofrece el contexto del aprovechamiento de la herencia cultural de las naciones pasadas y presentes de nuestro país, cuyos herederos directos, los indígenas, son tan caros a las emociones -los cuales intentan ocultar la indiferencia de muchos por la injusta práctica de marginación- de nuestro nacionalismo frente a los extranjeros.

En términos de motivación turística y sus componentes mercadológicos, un renglón relevante para el turismo cinegético del país lo constituye la legislación relativa a la pesca y caza deportiva que se encuentra regulada por cuatro disposiciones: la Ley de Pesca, la Ley Federal de Caza, la Ley General de Vida Silvestre y la Ley Federal de Armas de Fuego y Explosivos, la cual regula la posesión, tipos y permisos de armas así como las condiciones de su introducción al país. Si bien estas leyes norman las actividades turísticas, no siempre evitan la depredación de algunas especies de fauna marítima o terrestre del país. Por otra parte, la Ley de Juegos y Sorteos, en su momento y según como se vea, podría ser un lastre o el marco de acción de las actividades económicas orientadas al juego (los casinos), donde la experiencia de otros países -como Perú y Costa Rica- confirma una participación fundamentalmente nacional y local en el juego, el cual, si bien se considera complemento de las actividades lúdicas de los turistas y no como el mecanismo básico de competitividad, puede socavar la economía de las familias en contextos de pobreza histórica y de sueños y esperanzas nunca concretadas.

Desde el punto de vista de las relaciones comerciales, la Ley Federal de Protección Industrial se relaciona con el turismo cuando trata de los mecanismos vigentes de comercialización de los nombres y las marcas de productos de otras latitudes, y que utilizamos en México cada vez más, como si careciéramos de formas propias para dar las respuestas comerciales adecuadas al crecimiento de nuestros visitantes e incluso de nuestros conciudadanos. En este mismo sentido, la Ley de Competencia Económica, que vela por la equidad de las relaciones comerciales privadas (buscando, por ejemplo, la abolición de las prácticas monopólicas), se podría poner en entredicho por la arrolladora presencia de grandes y poderosos grupos que imponen sus propias condiciones al mercado. 
Una ley que establece el puente entre el derecho del consumidor y la responsabilidad de ofrecer información por parte de la empresa (así como la responsabilidad pública de acotar la acción de la empresa privada) es la Ley de Metrología y Normalización, que ha dado las pautas para la categorización de los comercios turísticos, tan importante para propios y extraños en la búsqueda de establecimientos que satisfagan realmente las expectativas del consumidor turístico, lo que da lugar a la creación de las Normas Oficiales Mexicanas (NOM) y las Normas Mexicanas (NMX). Las primeras son obligatorias y refieren básicamente aspectos de seguridad e higiene, mientras que las segundas son voluntarias $y$ tratan del siempre elusivo concepto de calidad; son éstas las que fomentan la asignación de categorías a los servicios para ser reconocidos por los diferentes segmentos del mercado.

Es en el ámbito definido por Jiménez como de vinculación en el sistema turístico (2005, pp: 73), donde se encuentran empresas y actores sujetos de la interacción turística. A las regulaciones del contexto macro del ámbito receptor, le son necesarias las del contexto micro o empresarial que norman la conducta comercial y laboral: las leyes asociados a la constitución de sociedades mercantiles o de otro tipo (Ley de Sociedades de Inversión, Ley General de Sociedades Cooperativas, Ley General de Sociedades Mercantiles, Ley de Sociedades de Responsabilidad Limitada de Interés y la Ley de Sociedades de Solidaridad Social), el Código de Comercio, el Código Fiscal de la Federación, la Ley Federal de Trabajo y la Ley del Impuesto al Valor Agregado, incluida la miscelánea fiscal y la dinámica de sus modificaciones. Otras leyes y ordenamientos relacionados con las prácticas comerciales lo serían el Derecho Aduanero que aplica y resulta muy importante para las actividades de congresos y convenciones.

El Código Penal Federal establece las responsabilidades de las prácticas comerciales y deportivas, incluidas las dificultades potenciales de las actividades turísticas de alto riesgo (como pueden ser las prácticas ecoturísticas, buceo y espeleología). Finalmente, se tendrían la Ley del Impuesto al Activo y la Ley del Impuesto sobre la Renta, que estipulan las obligaciones fiscales de los ciudadanos y de los empresarios, y suponen -aunque no siempre sea muy claro- una correspondencia con los servicios que ofrece el Estado.

Finalmente, la Ley de Cámaras Empresariales y sus Confederaciones señala la obligación de asociación de los subsectores, lo que posibilita la acción 
conjunta y ordenada de diferentes intereses en juego; aunque, en el desarrollo de los grandes temas del turismo internacional y nacional en México, sólo hasta hace poco empieza a ser clara la participación de los subsectores como grupos de presión. Un ejemplo de ello lo fue el tema de los casinos y, más recientemente, los temas relativos a la aplicación de la Ley de laVida Silvestre y la posibilidad de construir nuevas instalaciones a pesar de la protección de los manglares.

Otras leyes vinculantes con la información y planeación para el desarrollo del turismo en el país en el ámbito del sector público son, respectivamente, la Ley de Información Estadística y Geográfica y la Ley de Planeación. La primera dispone el marco normativo donde se puede obtener y generar la información necesaria para la conducción de la política turística del país; la segunda obliga al Ejecutivo Federal a definir con antelación las pautas del juego del Estado para el desarrollo armónico del país.

En la reflexión que se hace de la jura del país, no podemos dejar de mencionar el espíritu de justicia del Derecho, que nos llevaría, en las actividades turísticas, a colocar los intereses de nuestros conciudadanos en la premisa de las decisiones. Y si bien la Ley de Protección al Consumidor ofrece el marco de los reclamos por la insatisfacción del consumo de bienes y servicios, incluidos los del turismo, tendremos que reconocer que hay derechos de las distintas comunidades turísticas del país, que aún están pendientes para los anfitriones marginados de muchas localidades turísticas.

En ese sentido, en la relación huésped-anfitrión, esencia del turismo en su dimensión humana, debería prevalecer la justicia implícita en el derecho de las comunidades locales a decidir y proteger su entorno de las ambiciones lúdicas de los turistas y de los que viven del turismo; así como mejorar la distribución del ingreso entre las poblaciones que se resisten a ser tratadas sólo como anfitrionas de escenografía, sin participar de muchos de los beneficios económicos que el turismo acarrea.

En las escuelas y facultades de Turismo es el Derecho uno de los temas relevantes con respecto a la praxis turística, que debe intentar ofrecer un marco amplio y adecuado de la función turística y jurídica del país, sin la reducción simplista de las prácticas ligadas de manera específica con nombres turísticos. El vínculo de la relación de los actores con la realidad del viaje, se puede traducir sintéticamente para el caso del turismo, en el respeto por el otro (el turista) y la 
preocupación por el bienestar de la población local. Las herramientas jurídicas están allí, sólo hace falta su implementación puntual, consciente y amplificada.

Las leyes mencionadas y su fecha de publicación o de entrada en vigor, se presentan a continuación de acuerdo con el ámbito del sistema turístico referido.

Legislación en el ámbito receptor

I. Constitución Política de los Estados Unidos Mexicanos de 1917 y todas sus reformas.

2. Ley General de Población (septiembre de 1973)

3. Ley General de Equilibrio Ecológico y de Protección al Ambiente (primera versión en 1988 y una versión actualizada el 13 de diciembre de 1996)

4. Ley de Pesca (25 de junio de 1992)

5. Ley Federal de Caza (6 de enero de 1952)

6. Ley Federal de Armas de Fuego y Explosivos (29 de diciembre de 197I, con las últimas reformas de diciembre de 1995)

7. Ley General de Vida Silvestre (25 de abril de 2000)

8. Ley del Mar (8 de enero de 1986)

9. Ley de Navegación (diciembre de 1993) y la Ley de Navegación y de Comercio (enero de 1963)

10. Ley de Puertos (I de julio de 1973, con reformas en mayo del 2000)

II. Ley de Aeropuertos (diciembre de 1995)

12. Ley de Aviación Civil ( abril de 1995)

13. Ley de Vías Generales de Comunicación (30 de diciembre del939, con las últimas reformas en 1995)

14. Ley de Caminos, Puentes y Autotransporte Federal (I3 de diciembre de 1993)

15. Ley Agraria (26 de febrero de 1992)

16. Ley de Asentamientos Humanos (2I de julio de 1993)

17. Ley de Aguas Nacionales (I de diciembre de 1992)

18. Ley General de Desarrollo Forestal Sustentable (23 de mayo de 2003)

19. Ley Federal de Turismo (31 de diciembre de 1992. Reglamento. Las últimas reformas son del 19 de abril de 1999 donde se constituye el Consejo de Promoción Turística de México y se le asignan recursos a la promoción derivados de una parte de los impuestos migratorios [DNI]) 
20. Ley Federal de Metrología y Normalización (I de julio de 1992)

21. Ley Federal de Protección al Consumidor (diciembre de 1992, reformada en 1994 y en el 2000)

22. Ley de Títulos y Operaciones de Crédito (agosto de 1932)

23. Ley de Competencia Económica (18 de diciembre de 1992)

24. Ley Federal de Derechos (I de enero de 1982)

25. Ley General de Salud (26 de diciembre de 1983). Estipula regulaciones para la sanidad marítima, aérea y terrestre; para la publicidad y para los productos cosméticos y de belleza (por los spa); también para las enfermedades transmisibles (como el sida). Las últimas reformas son del 2000, 2002 y 2003.

26. Ley Federal de Juegos y Sorteos (diciembre de 1947)

27. Ley de la Propiedad Industrial (junio de 1991)

28. Ley de Inversión Extranjera (de 1973, con la última reforma del 15 de diciembre de 1995)

29. Ley General de Bienes Nacionales (22 de diciembre de $198 \mathrm{I}$ con la última reforma del 29 de julio de 1994)

30. Ley Federal de Monumentos y Zonas Arqueológicas, Artísticas e Históricas (del 28 de abril de 1972)

3I. Ley de Desarrollo Rural Sustentable ( I 3 de noviembre del 200 I)

Legislación en el ámbito de la administración pública

I. Ley de Información Estadística y Geográfica (23 de diciembre de 1980)

2. Ley de Planeación (29 de diciembre de 1982)

3. Ley Orgánica de la Administración Pública Federal (1976 y sus reformas)

4. Ley de Presupuesto, Contabilidad y Gasto Público (1976 y sus reformas)

5. Ley Federal de Entidades Paraestatales (1986 y sus reformas)

6. Ley sobre la Celebración de Tratados (1992)

Legislación en el ámbito de la administración privada

I. Ley Federal de Trabajo (I de mayo de 1970)

2. Código Fiscal de la Federación (30 de diciembre de 198I)

3. Ley del Impuesto sobre la Renta (I de enero de 2002) 
4. Ley del Impuesto al Valor Agregado (I de enero de 1979, con la última reforma al 30 de diciembre de 2002)

5. Código de Comercio ( 1890 y con las últimas modificaciones al 20 de marzo de 2000)

6. Derecho Aduanero (16 de diciembre de 1995; es importante para congresos y convenciones)

7. Código Penal Federal (14 de agosto de 1931, con las reformas de 1996, 1999, 2000 y del 6 de febrero de 2002)

8. Ley de Sociedades de Inversión (28 de abril de 200I)

9. Ley General de Sociedades Cooperativas (I 3 de julio de 1994)

10. Ley General de Sociedades Mercantiles (I de agosto de 1934)

II. Ley de Sociedades de Responsabilidad Limitada de Interés (30 de agosto de 1934)

12. Ley de Sociedades de Solidaridad Social (26 de mayo de 1976)

13. Ley del Impuesto al Activo ( 30 de diciembre de 1988)

14. Ley de Cámaras Empresariales y sus Confederaciones (10 de diciembre de 1996)

\section{Conclusiones}

La acción turística tiene un amplio espectro de aplicación jurídica que rebasa la tradicional concepción de los involucrados en el turismo. Suma 3 I leyes donde se pueden prever impactos en las actividades turísticas dentro del ámbito receptor y seis más pueden ser atribuibles al ámbito de la administración pública federal, también del ámbito receptor, donde su aplicación es indispensable para darle sentido y orientación al desarrollo de la política turística del país. En el ámbito de vinculación, se refieren un total de 14 leyes adicionales aplicables a la esfera de la empresa privada donde existe obligatoriedad. En suma, parece indispensable tener plena conciencia del panorama general que existe en los diferentes ámbitos donde se verifican el desarrollo turístico y las regulaciones que conforman el marco jurídico que establece México. 
FUENTES CONSULTADAS

Jiménez Martínez,Alfonso de Jesús (2005). Una aproximación a la conceptualización del turismo desde la Teoría General de Sistemas. México. Universidad del Caribe / Porrúa.

León Gómez, Diana (2002). Introducción al Derecho turístico. México: Instituto Politécnico Nacional.

Ley Federal de Turismo (1995). México: Congreso de la Unión.

Olivera del Toro, Jorge (1988). Legislación y organización turística mexicana. $3^{\mathrm{a}}$ ed., México: Porrúa.

Sectur (1997). Legislación turística. México: Sectur.

Páginas electrónicas

Instituto de Investigaciones Históricas. http/:info.jurídicas.unam.mx

Monografías.com. http://www.monografias.com/trabajos /0/derech/derech. shtml 
